\title{
Temporal masking level differences for transients: Further evidence for a short-term integrator
}

\author{
KATHLEEN M. BERG \\ University of Florida, Gainesville, Florida
}

\begin{abstract}
Studies of binaural perception have indicated that subjects are able to use temporal information available in high-frequency regions of the spectrum to lateralize high-frequency waveforms but not to detect these waveforms in masking noise. The present experiments demonstrate that although high-frequency interaural difference cues are relatively ineffective in simultaneous and forward masking, they can be utilized in backward masking. In Experiment 1, large maskinglevel differences were found in backward masking for high-frequency transients presented either monaurally or with an interaural temporal delay. Experiments 2-4 examined fringe masking, effects of masker duration, and combined forward-backward masking for both high- and lowfrequency transients presented with interaural differences in phase and intensity. The results are interpreted as support for the view that the auditory system is organized into parallel short. and long-term integration systems specialized for processing transient and sustained aspects of acoustic stimulation. It is suggested that information from the two integrators is combined when analysis of interaural differences within each of the systems yields similar estimates of spatial location.
\end{abstract}

One of the many advantages of perceiving the world through two ears rather than one is the enhanced ability to distinguish signals from a background of interfering noise. When the interaural phase or temporal parameters of an auditory signal differ from those of a background masking noise, the signal may be detected at a much lower level than when interaural parameters of both the signal and noise are the same. This binaurally mediated increase in detectability is frequently referred to as the "cocktailparty" effect, and has been systematically investigated in the laboratory as the binaural masking-level difference, or MLD. Factors affecting the size of the MLD are also those that affect sound localization or lateralization, and the two phenomena are generally considered to be closely related.

A number of models have been developed to explain the various phenomena of binaural perception. Those most successful in accounting for the MLD have been the Webster-Jeffress model (Jeffress, 1972), which proposes that the MLD is based on detection of interaural time differences arising from the combination of the signal and noise waveforms present at each ear, and Durlach's (1972) equalization-cancellation model, in which a signal is extracted from noise by subtraction of the two monaural waveforms. Many aspects of these models have been elaborated and quantified in the more recent work of Colburn (1977; Colburn \& Durlach, 1978) based on firing patterns of the auditory nerve.

The author's mailing address is: Institute for Advanced Study of the Communication Processes, University of Florida, Gainesville, FL 32611.
An implicit assumption made by all of these models is that the signal and noise are present simultaneously. However, MLDs are also seen in both forward and backward temporal masking in which signal and masker do not overlap in time (e.g., Deatherage \& Evans, 1969; Dolan \& Trahiotis, 1972; Small et al., 1972). To account for these findings, it has been proposed that interaction occurs between neural representations of the signal and masker, and that detailed characteristics of the waveforms, including interaural phase and temporal information, are preserved until this interaction takes place (Dolan \& Trahiotis, 1972; Lakey, 1976). This paper reports a series of studies of the MLD in temporal masking which appear to require an alternative explanation.

\section{EXPERIMENT 1}

According to the traditional duplex theory of binaural hearing, the binaural system uses temporal cues in processing low-frequency signals and intensity cues at high frequencies. Early studies of lateralization performance demonstrated that subjects were unable to detect interaural temporal differences for frequencies higher than approximately $1500 \mathrm{~Hz}$. The size of the MLD also varied with signal frequency, decreasing from a maximum of about $15 \mathrm{~dB}$ at $250 \mathrm{~Hz}$ to a small constant value of $2-3 \mathrm{~dB}$ for frequencies higher than $1500 \mathrm{~Hz}$ (Green \& Yost, 1976).

It is now clear that the traditional view of binaural processing holds only for tonal stimuli. Within the past decade, a number of laboratories have repeatedly demonstrated that when stimuli are high-frequency complex 
waveforms rather than tones, subjects are able to extract temporal cues from the fluctuating envelope (e.g., Henning, 1974a, 1974b, 1980; McFadden \& Pasanen, 1976; Nuetzel \& Hafter, 1976; Young \& Carhart, 1974). One rather unexpected finding has been that although temporal cues present in the envelope of high-frequency stimuli are sufficient to support lateralization, they apparently cannot be used to enhance detection of these waveforms in masking noise. Only small MLDs of 1-2 dB have been reported for both high-frequency noise bands and amplitude-modulated tones that could be easily lateralized on the basis of interaural temporal or phase cues (Henning, 1974b; Henning \& Gaskell, 1981).

Similar results have been described for lateralization and binaural detection of brief transients. High-frequency transients presented with an interaural temporal delay are readily lateralized (Hafter \& DeMaio, 1975; Yost, 1976; Yost \& Silva, 1977; Yost, Wightman, \& Green, 1971), but although masking level differences on the order of 13-16 dB are typically found for low-frequency transients, MLDs no larger than 2-5 dB have been reported for either single or repeated presentations of high-frequency transients (Flanagan \& Watson, 1966; Henning \& Gaskell, 1981; Yost \& Dolan, 1978; Yost \& Silva, 1977; Zerlin, 1966). To date, all studies of the MLD for high-frequency stimuli have employed continuous or simultaneous masking, in which the masker and signal are physically present at the same time. Experiment 1 demonstrates another unexpected finding: that large MLDs for high-frequency transients can be obtained in temporal masking in which the signal and masker do not physically overlap.

\section{Method}

Both forward and backward temporal masking were examined for high-frequency transients presented monaurally and binaurally with interaural temporal delays of $0 \mu \mathrm{sec}$ (diotic condition) or 200 , 400 , and $800 \mu \mathrm{sec}$ (dichotic conditions). The clicks were generated from $100-\mu \mathrm{sec} d \mathrm{dc}$ pulses and bandpass filtered between 2000 and $8000 \mathrm{~Hz}$ by a Krohn-Hite Model 335 filter. Interaural delays were produced by an Ad-Yu Model 801 delay line. Delayed clicks were always delivered to the left ear; monaural clicks were always delivered to the right. Masking stimuli were 600 -msec bursts of broadband noise, low-pass filtered at $10 \mathrm{kHz}$ and presented binaurally in phase at a spectrum level of $35 \mathrm{~dB}$ SPL with no additional rise-decay shaping. For both forward and backward masking conditions, intervals beween the click and masker were 1, 3, 6,10 , and $30 \mathrm{msec}$, as measured from masker onset or offset to the nondelayed click. Detectability of the click stimuli was also examined in simultaneous masking; for these conditions, the click was temporally centered within the 600 -msec noise burst. All stimuli were delivered through TDH-39 headphones mounted in circumaural cushions.

Three normal-hearing persons served as subjects. Two were experienced listeners who had previously served in similar experiments, and all three received a minimum of $5 \mathrm{~h}$ of practice before data collection was initiated.

Thresholds were obtained using an adaptive two-alternative forced-choice procedure. Each trial began with a 300-msec warning light, followed by a 300-msec pause and two observation intervals. Subjects responded either "first" or "second" during a 1.5sec response period, and the trial was then terminated with a 600 -msec feedback light indicating which of the two intervals had contained the signal. The observation intervals varied from 600 to $630 \mathrm{msec}$ in duration, depending on occurrence of the click, and were separated by a $300-\mathrm{msec}$ pause. For each condition, the subjects were informed of the temporal location of the click relative to the masker and all conditions for a given type of masking were completed before testing of the next type was begun. Click intensity was increased by $1 \mathrm{~dB}$ after a single incorrect response and decreased by the same amount after two consecutive correct responses, a procedure that yields an estimate of approximately $71 \%$ correct detection (Levitt, 1971). Each run was terminated after nine up-down reversals, and the mean click intensity over the last six reversals was taken as threshold. The final threshold estimate for each observer and condition represented the mean of three or, if the range over three runs exceeded $3 \mathrm{~dB}$, four independent threshold determinations. The amount of masking (masked click level) was expressed as the difference between threshold for detection of the clicks in a background of quiet and under the various masking conditions.

\section{Results and Discussion}

The pattern of results was very similar for all three listeners, and their data are shown averaged for each of the masking conditions in Figure 1. Masking-level differences are computed as the difference between thresholds for the diotic reference condition $(0 \mu \mathrm{sec})$ and the various dichotic conditions. Values plotted at the point labeled " $C$ "' are those obtained for simultaneous masking, when the click was centered within the noise burst.

Temporal masking functions for both diotic and dichotic click stimuli follow the pattern typically reported in studies of nonsimultaneous masking; thresholds gradually decreased as the interval between click and masker increased from 1 to $30 \mathrm{msec}$, but declined more steeply for backward than for forward masking conditions. Results for simultaneous masking are also in good agreement with those reported previously. When clicks were centered within the noise burst, there was virtually no masking-level

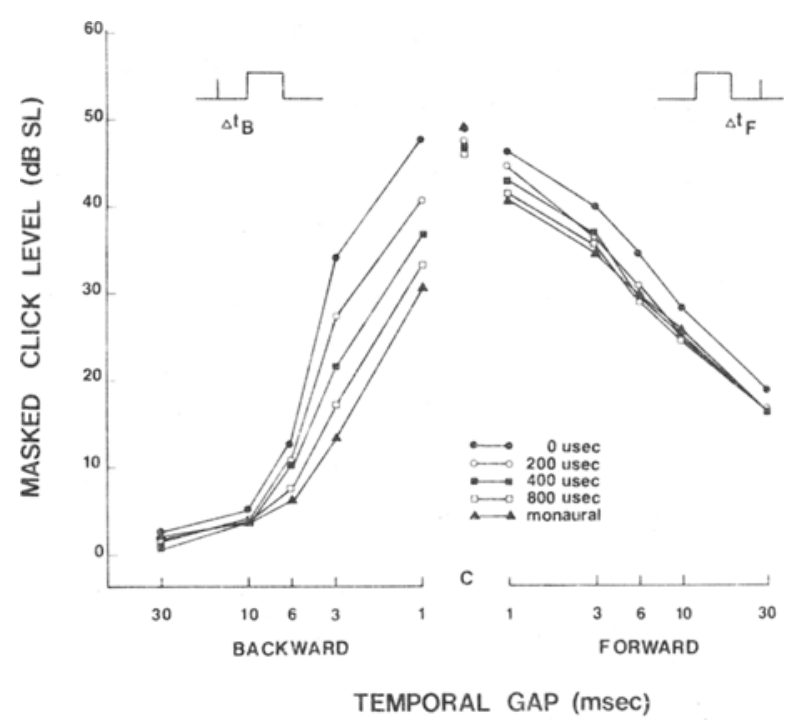

Figure 1. Thresholds in decibels SL for high-frequency transients in forward, backward, and simultaneous masking. The masker was a diotic broadband noise; transients were presented either monaurally or with an interaural temporal delay ranging from 0 to $800 \mu$ sec. Data are means of three subjects. 
difference for the monaural transient. For interaural delay conditions, MLDs tended to increase slightly as the delay increased from 200 to $800 \mu \mathrm{sec}$, but the differences were consistently small and no subject showed an MLD larger than $5 \mathrm{~dB}$ for any interaural delay. These values are in the same range as the MLDs reported by Yost and Dolan (1978) and Yost and Silva (1977) for single highpass transients presented with an interaural temporal delay in continuous masking noise.

Results for forward masking were similar to those for simultaneous masking, showing small MLDs, in the range of 3-6 dB, which persisted even as the amount of masking declined with increased temporal gap size. A notable exception was the monaural click, which showed no MLD for simultaneous masking, but yielded MLDs on the order of 5-6 dB for all three subjects under forward-masking conditions.

In contrast to the small differences seen among simultaneous- and forward-masking conditions, sizable MLDs were obtained in backward masking. These were largest for a temporal gap of $3 \mathrm{msec}$, where MLDs increased from 6 to $17 \mathrm{~dB}$ as interaural delay increased from 200 to $800 \mu \mathrm{sec}$. MLDs for the monaural click were even larger, averaging $20.6 \mathrm{~dB}$ for the same temporal gap.

Since MLDs of this magnitude have not been previously reported for high-frequency stimuli, it seemed prudent to verify that the subjects were actually detecting highfrequency temporal cues. Studies of lateralization performance utilizing both filtered clicks (Yost et al., 1971) and bands of noise (Bernstein \& Trahiotis, 1982) have indicated that even when stimuli contain mostly high frequencies, subjects tend to base lateralization judgments primarily on low-frequency information. To determine whether the large high-frequency MLDs seen in backward masking were actually due to detection of interaural differences in the low-frequency region of the spectrum, the diotic reference condition and two dichotic conditions were repeated in the presence of either a low-pass $(.5-2000 \mathrm{~Hz})$ or a high-pass $(2000-10000 \mathrm{~Hz})$ continuous masking noise. This task was performed by two new observers, one of whom was the author. For these subjects, the interval between the click and backward masker was fixed at $1 \mathrm{msec}$ and the click was presented monaurally and binaurally with interaural delays of 0 and $800 \mu \mathrm{sec}$. The background noise was generated by an independent source and presented at a spectrum level of $35 \mathrm{~dB}$ for both lowand high-pass masking conditions.

Thresholds for the three temporal masking conditions in backgrounds of quiet and filtered noise are listed for the two observers in Table 1. In agreement with the findings reported above, both subjects showed large MLDs for both monaural and interaurally delayed clicks when the stimuli were presented in a background of quiet. These MLDs were decreased by the addition of either low-pass or high-pass continuous noise. For one observer (K.B.), MLDs were reduced by approximately the same amount by the introduction of either noise background. For the other, high-pass noise was more effective than low-pass noise in reducing the size of the MLD. These results are therefore consistent with previous work suggesting that subjects may use information from low-frequency regions to detect interaural differences in nominally highfrequency stimuli. However, the reduction of MLDs in the presence of high-pass background noise indicates that their judgments were not based on low-frequency information alone. Rather, interaural differences in both lowand high-frequency regions of the spectrum appear to contribute to the temporal MLD.

The most striking result of Experiment 1 is that MLDs for high-frequency transients were small or nonexistent in simultaneous masking, where the click and masker clearly overlapped, but were large in backward masking, where they did not. This dissociation would not be predicted by theories of masking that assume that the processes underlying temporal and simultaneous masking are basically similar. However, stimulus onsets are known to play a special role in binaural perception, and it is possible that transients may invoke specialized mechanisms involved in the binaural phenomenon of precedence. This possibility was examined in Experiment 2.

\section{EXPERIMENT 2}

Precedence is not a well-defined term, but generally refers to the fact that perception of the location of a sound source is dominated by its onset. One aspect of the phenomenon is the ability of the binaural system to "suppress" ambiguous auditory reflections and echoes in a reverberant environment (Durlach \& Colburn, 1978). In

Table 1

Thresholds in Decibels SL and MLDs for Three Temporal Masking Conditions in Backgrounds of Quiet and Low- and High-Pass Continuous Noise

\begin{tabular}{|c|c|c|c|c|c|c|c|}
\hline \multirow[b]{2}{*}{ Subject } & \multirow{2}{*}{$\begin{array}{l}\text { Interaural } \\
\text { Condition }\end{array}$} & \multicolumn{2}{|c|}{ Quiet } & \multicolumn{2}{|c|}{ Low-Pass } & \multicolumn{2}{|c|}{ High-Pass } \\
\hline & & Threshold & MLD & Threshold & MLD & Threshold & MLD \\
\hline T.W. & $\begin{array}{l}0 \mu \mathrm{sec} \\
800 \mu \mathrm{sec} \\
\text { monaural }\end{array}$ & $\begin{array}{l}47.1 \\
23.0 \\
23.6\end{array}$ & $\begin{array}{l}24.1 \\
23.5\end{array}$ & $\begin{array}{l}41.5 \\
25.4 \\
26.0\end{array}$ & $\begin{array}{l}16.1 \\
15.5\end{array}$ & $\begin{array}{l}40.5 \\
31.9 \\
34.4\end{array}$ & $\begin{array}{l}8.6 \\
6.1\end{array}$ \\
\hline K.B. & $\begin{array}{l}0 \mu \mathrm{sec} \\
800 \mu \mathrm{sec} \\
\text { monaural }\end{array}$ & $\begin{array}{l}46.9 \\
30.8 \\
26.9 \\
\end{array}$ & $\begin{array}{l}16.1 \\
20.0\end{array}$ & $\begin{array}{l}44.0 \\
38.9 \\
37.7 \\
\end{array}$ & $\begin{array}{l}5.1 \\
6.3\end{array}$ & $\begin{array}{l}51.2 \\
44.6 \\
47.7 \\
\end{array}$ & $\begin{array}{l}6.6 \\
3.5\end{array}$ \\
\hline
\end{tabular}


a detailed study of this echo-suppressing ability, Zurek (1979) demonstrated that, for a brief period of approximately 5-10 msec after onset of a diotic stimulus, an interaurally delayed "echo" is less detectable than a nondelayed one. If presentation of an interaurally delayed click were able to suppress a subsequent diotic masker in a similar manner, such a mechanism could account for the large MLDs seen for the backward-masking conditions in Experiment 1.

Some support for this notion has been provided by studies of binaural "fringe" masking reported by McFadden (1966) and Robinson and Trahiotis (1972), although the stimuli and time course of effects were quite different. In both studies, low-frequency tones were presented either interaurally in phase or with an interaural phase reversal at various delays after onset of a diotic masker. The results indicated that although masker-signal delay had little effect on performance for the diotic signal, detectability of the phase-reversed signal was poorest when the masker and signal began simultaneously and improved by as much as $9 \mathrm{~dB}$ as the delay between masker onset and the signal increased to approximately $600 \mathrm{msec}$.

Experiment 2 attempted to test a "binaural suppression"' hypothesis of the high-frequency temporal MLD by examining detectability of clicks presented within a brief interval after onset of a diotic noise masker. On the basis of Zurek's (1979) findings, it was expected that detectability of dichotic clicks would be poor immediately after masker onset and improve as masker-click delay increased beyond $10 \mathrm{msec}$. Since the delay between a signal and the offset of a masker has also been found to affect performance for dichotic tonal stimuli (Trahiotis, Dolan, \& Miller, 1972), detectability was examined for clicks presented within the brief period immediately before masker offset as well.

\section{Method}

In addition to the high-pass $(2000-8000 \mathrm{~Hz})$ clicks used in the previous study, Experiment 2 also employed low-pass $(.5-2000 \mathrm{~Hz})$ clicks and manipulated interaural phase rather than interaural temporal differences. Both high- and low-pass clicks were presented under homophasic (NoSo), antiphasic (NoS $\pi$ ), and monaural (NoSm) masking conditions. The masker was a 1,200-msec broadband noise presented diotically at a spectrum level of $25 \mathrm{~dB}$ SPL. Stimuli were presented in forward and backward fringe-masking configurations, in which the click occurred just after masker onset or just prior to masker offset, and also in forward and backward temporal masking configurations. Intervals between the click and masker onset or offset were $1,3,6,10,20$, and $30 \mathrm{msec}$. In addition, subjects were tested with the click centered within the 1,200msec masker to provide a continuous masking comparison. Two observers who had participated in the first part of Experiment 1 served as subjects. All other procedures were identical to those described previously.

\section{Results and Discussion}

Results for the two subjects were in close agreement, and their data have been averaged in Figure 2 for each of the experimental conditions. The points $T$ and $T_{0}$ represent masker onset and offset, respectively, and values

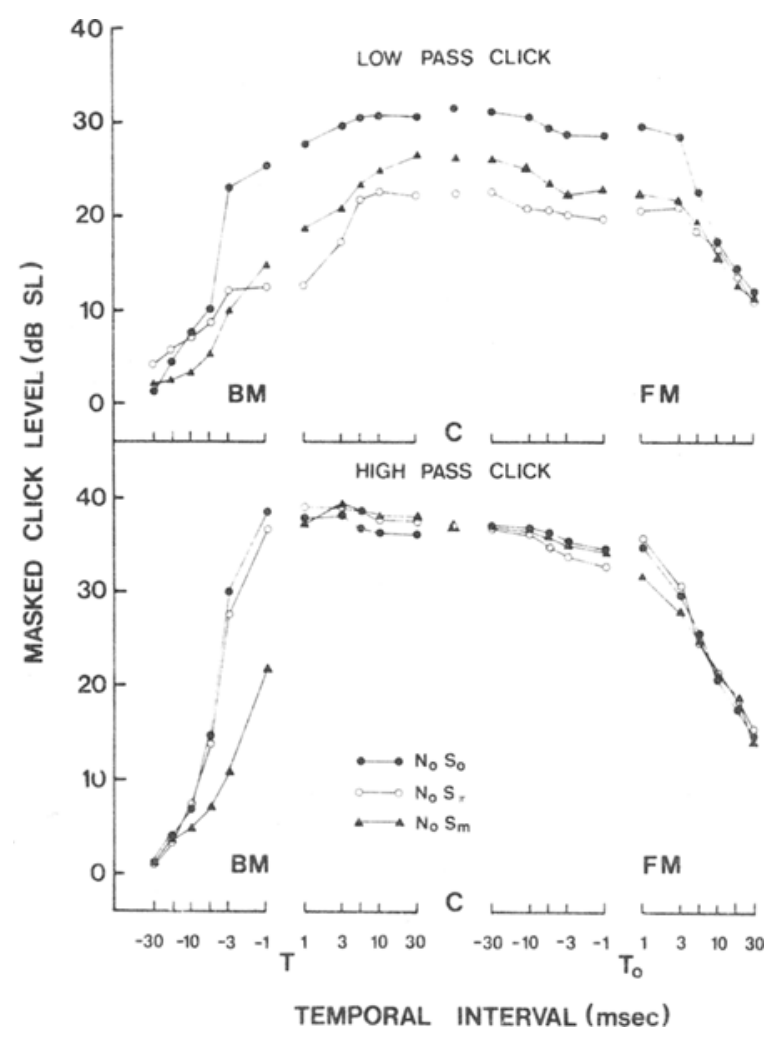

Figure 2. Thresholds in decibels SL for low- and high-frequency transients in forward and backward temporal masking, forward and backward fringe masking, and "continuous masking." Stimuli were presented in homophasic, and antiphasic, and monaural masking conditions. The points $T$ and $T_{0}$ represent masker onset and offset, respectively. Data are means of two subjects.

plotted at point $\mathrm{C}$ are those obtained when the click was centered within the masking noise.

Temporal masking. For the high-pass click, temporal masking functions were very similar to those found in Experiment 1; masking-level differences for the monaural click were very large, on the order of 17-19 dB, in backward masking, but no larger than $3 \mathrm{~dB}$ in forward masking. In contrast, MLDs for the high-pass $S \pi$ click did not exceed $2 \mathrm{~dB}$ for either backward or forward-masking conditions. Results for the NoS $\pi$ condition are therefore consistent with the large body of evidence indicating that although the binaural system is able to detect interaural differences in a stimulus envelope at high frequencies, it is insensitive to cycle-by-cycle differences in phase (Durlach \& Colburn, 1978). Temporal masking functions for diotic and dichotic low-pass clicks were also similar to those previously reported for transients containing lowfrequency energy. Masking-level differences exceeded $10 \mathrm{~dB}$ for both $\mathrm{Sm}$ and $\mathrm{S} \pi$ clicks, and were larger in backward- than in forward-masking conditions. Berg and Yost (1976) reported a similar difference in the size of MLDs in backward and forward masking for broadband transients. 
Fringe masking. Neither high- nor low-pass clicks showed the predicted decrease in detectability immediately after masker onset. For high-pass clicks, mean thresholds for both dichotic and diotic stimuli presented within $30 \mathrm{msec}$ of masker onset approximated those obtained in continuous masking, and the range of thresholds did not exceed $3 \mathrm{~dB}$ for either subject. Unexpectedly, dichotic low-pass clicks were more, rather than less, detectable during this interval. The effect on performance was most striking for the NoS $\pi$ condition, where there was a 10- $\mathrm{dB}$ decrease in masked threshold as masker-click delay was reduced from 10 to $1 \mathrm{msec}$. There was also a noticeable increase in detectability for clicks presented immediately before masker offset, but the improvement in performance was smaller, on the order of $3 \mathrm{~dB}$, and was present for diotic as well as dichotic stimulus conditions. A similar 3- to 4- $\mathrm{dB}$ decrease in threshold at the fringes of a noise burst has been reported by Wilson and Carhart (1971) for monaural clicks presented simultaneously with a monaural masker.

These data clearly indicate that there is no observable suppression of dichotic transients presented within a brief interval after onset of a diotic masker, and that suppression-type interactions between onsets of diotic and dichotic stimuli cannot account for the high-frequency MLD in backward masking. In the absence of alternative explanations, these results suggest that at least a portion of the masking evident in backward-masking paradigms occurs at sites that are central to the point of binaural interaction rather than at more peripheral sites, and that the extent of this central masking depends upon interaural parameters of the stimuli.

The finding that detectability for low-frequency dichotic transients was enhanced rather than reduced during the initial portion of the masker is especially puzzling in view of the reduction in detectability reported for low-frequency tones (McFadden, 1966; Robinson \& Trahiotis, 1972), and for noise bursts (Zurek, 1979) presented under similar conditions. The fact that MLDs for low-pass clicks presented both immediately before and immediately after masker onset were larger than those seen in continuous masking suggests that MLDs for low-frequency transients may be determined by two independent mechanisms: one that detects interaural phase differences in ongoing stimulation and a second which is operative only in the vicinity of masker onset.

\section{EXPERIMENT 3}

The occurrence of large MLDs for high-frequency transients in backward, but not in simultaneous, masking appears to pose a problem not only for current models of binaural detection, but also for theories that attempt to explain backward masking in terms of interference between signal and masker excitation patterns in the auditory periphery (e.g., Duifhuis, 1973; Lakey, 1976). An alternative approach to temporal masking has been to treat it within the context of the hypothesis of a running aver- age or temporal integrating period. This hypothesis, originally proposed to account for the phenomena of temporal summation (Munson, 1947; Zwislocki, 1960, 1969), assumes that the basis for a subject's response is not the instantaneous auditory input, but the auditory input weighted by a time-averaging function. Applied to temporal masking, this model predicts that detectability of a signal will decrease as it is moved closer to a masker because the weighting function encompasses more noise. For the same reason, detectability should also decrease with increases in masker duration as long as the period of integration is not exceeded. For diotic clicks centered within a noise masker, thresholds have been found to increase as masker duration is increased to $20-30 \mathrm{msec}$ and then to remain constant (Penner \& Cudahy, 1973; Penner, Robinson, \& Green, 1972). In temporal masking, the interval over which increases in masker duration are effective varies with the interval between the click and noise burst, but asymptotic durations are generally longer than in simultaneous masking (Penner, 1974; Penner, Cudahy, \& Jenkins, 1974).

Although comparable data are not available for dichotically presented transients, studies employing brief tonal signals have indicated that the size of the MLD increases with increasing masker duration in both simultaneous (Zwicker \& Zwicker, 1984) and temporal masking (Lakey, 1976), suggesting that there may be differences in the integration process for diotic and dichotic stimuli. Experiment 3 addressed this question by examining the effect of masker duration on thresholds for both diotic and dichotic high- and low-pass transients in temporal masking.

\section{Method}

Stimuli were the same high- and low-pass transients employed in the previous study. They were presented in both forward and backward masking configurations, with the silent interval betwen click and masker fixed at $3 \mathrm{msec}$ for both types of masking. The diotic noise masker was presented with durations of $1,3,6,10$, $30,100,300$, and $1,000 \mathrm{msec}$ at a spectrum level of $35 \mathrm{~dB}$ SPL. Duration of the observation intervals was held constant at $1 \mathrm{sec}$ for all masker durations. Homophasic (NoSo) and monaural (NoSm) masking conditions were examined for both low- and high-pass transients; for the low-pass click, thresholds were determined for the antiphasic (NoS $\pi$ ) condition as well. Other procedures were the same as those described previously, and subjects were the same two observers who served in Experiment 2.

\section{Results and Discussion}

The effect of increasing masker duration in a forward masking paradigm is shown separately for each of the two observers in Figure 3. Results for low- and high-pass transients are presented in the left and right panels of the figure, respectively. Although relative thresholds for the various conditions were somewhat different for the two subjects, the data clearly show an increase in forward masking with increasing duration of the masker for both diotic and dichotic stimuli. For diotic clicks, functions relating click threshold to masker duration typically increased up to at least $100 \mathrm{msec}$, an asymptotic mask du- 


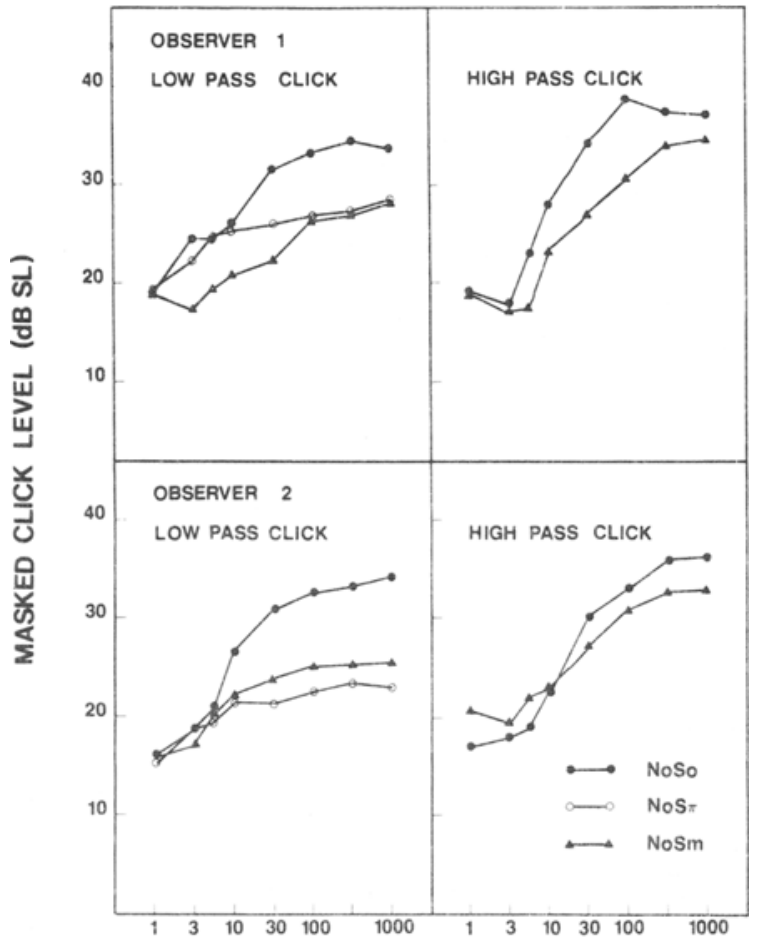

MASKER DURATION (msec)

Figure 3. Thresholds for low- and high-frequency diotic and dichotic transients as a function of forward-masker duration. The silent interval between forward-masker offset and the click was 3 msec. Upper and lower panels illustrate data for individual subjects.

ration similar to that reported by Penner (1974; Penner et al., 1974) for comparable temporal masking conditions. In agreement with the results reported by Lakey (1976) for brief tonal signals, the slopes of the functions were more shallow for dichotic clicks, but the interval over which increases in masker duration were effective did not appear to be markedly different for diotic and dichotic conditions.

Figure 4 illustrates results obtained for the two observers in backward masking. In general, the effect of variations in duration of the masker were less pronounced than in forward masking, a finding also reported by Lakey (1976) for brief tones. For monaural stimuli, in particular, increases in backward-masker duration produced only small increases in threshold for both low- and high-pass transients. However, the most interesting aspect of these data is the difference between forward- and backwardmask-duration functions for the high-pass monaural click. As masker duration increased from 1 to $1,000 \mathrm{msec}$, increases in threshold for the diotic high-pass click were nearly equivalent in forward and backward masking, averaging 18.5 and $17.2 \mathrm{~dB}$. In contrast, comparable increases in threshold of the monaural click averaged $14.0 \mathrm{~dB}$ in forward masking and only $2.1 \mathrm{~dB}$ in backward masking. A dichotic click that occurs prior to the onset of a masker therefore appears to be processed quite differently from one that occurs after its offset. Within the context of the temporal summation model, these data suggest that in forward masking a high-frequency dichotic click is integrated with the masker whereas in backward masking it is not.

\section{EXPERIMENT 4}

A number of investigators interested in the mechanisms of temporal masking have examined the effect of temporally nonoverlapping maskers presented in combination. For some combinations of masker intensities, durations, and temporal intervals, the amount of masking produced is greater than the sum of the effects of each of the maskers presented separately. This increment above the intensity sum of the separate maskers has been labeled "additional masking."

Penner (1980) examined additional masking for several conditions in which intervals between stimuli were very brief and argued that results obtained in these instances could be best explained by a model that included an initial short-term integrator operating in series with a second integrator of longer temporal extent. Much of the data reported in the preceding experiments would be consistent with the notion of a short-term integrator if it is as-

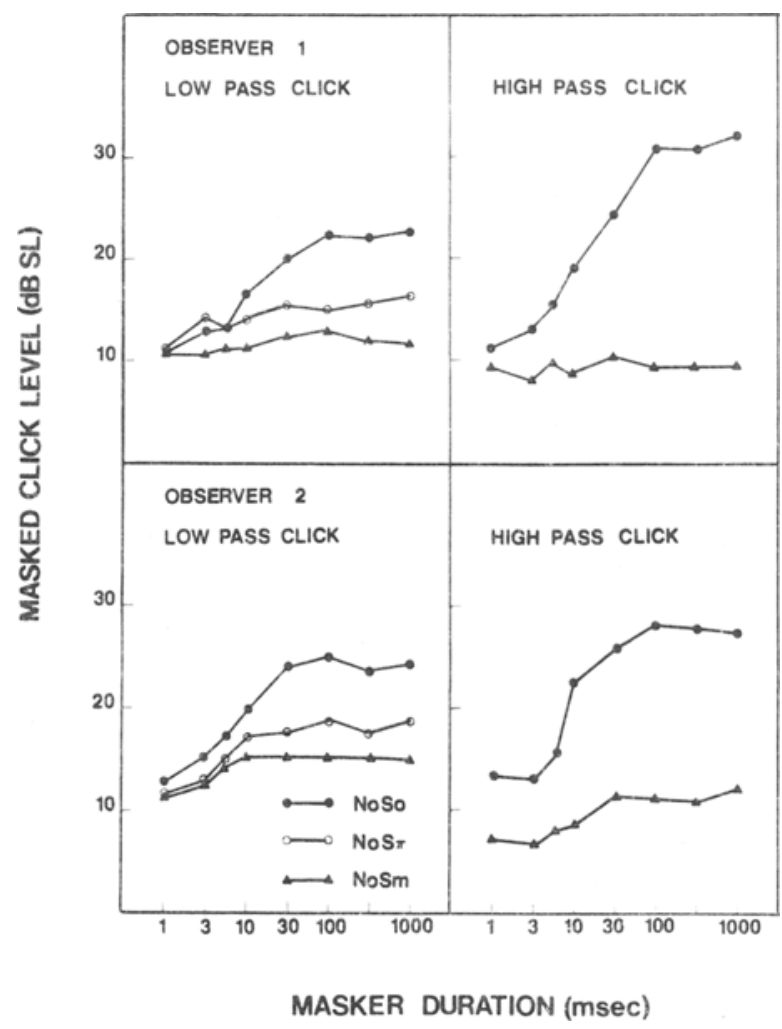

Figure 4. Thresholds for low- and high-frequency diotic and dichotic transients as a function of backward-masker duration. The silent interval between the click and backward-masker onset was 3 msec. 
Table 2

Thresholds in Decibels SL for Low-Pass Transients in Forward, Backward, and Combined Forward-Backward Masking for Masker Durations of 3 and 300 msec

\begin{tabular}{|c|c|c|c|c|c|c|c|}
\hline \multirow{2}{*}{$\begin{array}{l}\text { Interaural } \\
\text { Condition }\end{array}$} & \multirow{2}{*}{$\begin{array}{c}\text { Masker } \\
\text { Duration (F-B) }\end{array}$} & \multicolumn{3}{|c|}{ Observer 1} & \multicolumn{3}{|c|}{ Observer 2} \\
\hline & & Forward & Backward & Combined & Forward & Backward & Combined \\
\hline NoSo & $\begin{array}{l}300-300 \\
300-3 \\
3-300 \\
3-3\end{array}$ & $\begin{array}{l}34.1 \\
34.1 \\
24.3 \\
24.3\end{array}$ & $\begin{array}{l}33.5 \\
28.8 \\
33.5 \\
28.8\end{array}$ & $\begin{array}{l}38.0 \\
34.1 \\
37.4 \\
30.8\end{array}$ & $\begin{array}{l}34.3 \\
34.3 \\
24.9 \\
24.9\end{array}$ & $\begin{array}{l}27.9 \\
22.0 \\
27.9 \\
22.0\end{array}$ & $\begin{array}{l}36.7 \\
34.2 \\
34.1 \\
28.7\end{array}$ \\
\hline $\operatorname{NoS} \pi$ & $\begin{array}{l}300-300 \\
300-3 \\
3-300 \\
3-3\end{array}$ & $\begin{array}{l}26.8 \\
26.8 \\
23.0 \\
23.0\end{array}$ & $\begin{array}{l}13.0 \\
14.2 \\
13.0 \\
14.2\end{array}$ & $\begin{array}{l}28.6 \\
25.3 \\
25.1 \\
23.9\end{array}$ & $\begin{array}{l}21.9 \\
21.9 \\
21.6 \\
21.6\end{array}$ & $\begin{array}{l}14.4 \\
16.1 \\
14.4 \\
16.1\end{array}$ & $\begin{array}{l}25.4 \\
23.3 \\
23.2 \\
21.7\end{array}$ \\
\hline NoSm & $\begin{array}{l}300-300 \\
300-3 \\
3-300 \\
3-3\end{array}$ & $\begin{array}{l}28.7 \\
28.7 \\
22.1 \\
22.1\end{array}$ & $\begin{array}{l}16.7 \\
12.4 \\
16.7 \\
12.4\end{array}$ & $\begin{array}{l}32.4 \\
28.5 \\
28.7 \\
26.3\end{array}$ & $\begin{array}{l}25.2 \\
25.2 \\
21.0 \\
21.0\end{array}$ & $\begin{array}{l}18.5 \\
16.4 \\
18.5 \\
16.4\end{array}$ & $\begin{array}{l}31.8 \\
26.8 \\
26.8 \\
27.7\end{array}$ \\
\hline
\end{tabular}

Table 3

Thresholds in Decibels SL for High-Pass Transients in Forward, Backward, and Combined Forward-Backward Masking for Masker Durations of 3 and 300 msec

\begin{tabular}{|c|c|c|c|c|c|c|c|}
\hline \multirow{2}{*}{$\begin{array}{l}\text { Interaural } \\
\text { Condition }\end{array}$} & \multirow{2}{*}{$\begin{array}{c}\text { Masker } \\
\text { Duration (F-B) }\end{array}$} & \multicolumn{3}{|c|}{ Observer 1} & \multicolumn{3}{|c|}{ Observer 2} \\
\hline & & Forward & Backward & Combined & Forward & Backward & Combined \\
\hline NoSo & $\begin{array}{l}300-300 \\
300-3 \\
3-300 \\
3-3\end{array}$ & $\begin{array}{l}43.2 \\
43.2 \\
29.1 \\
29.1\end{array}$ & $\begin{array}{l}42.5 \\
35.6 \\
42.5 \\
35.6\end{array}$ & $\begin{array}{l}46.3 \\
45.1 \\
47.8 \\
47.7\end{array}$ & $\begin{array}{l}45.8 \\
45.8 \\
36.2 \\
36.2\end{array}$ & $\begin{array}{r}45.4 \\
38.0 \\
45.4 \\
38.0\end{array}$ & $\begin{array}{l}49.4 \\
49.0 \\
49.2 \\
48.5\end{array}$ \\
\hline NoSm & $\begin{array}{l}300-300 \\
300-3 \\
3-300 \\
3-3\end{array}$ & $\begin{array}{l}37.1 \\
37.1 \\
25.7 \\
25.7\end{array}$ & $\begin{array}{l}27.4 \\
21.8 \\
27.4 \\
21.8\end{array}$ & $\begin{array}{l}44.4 \\
41.0 \\
47.1 \\
43.2\end{array}$ & $\begin{array}{l}39.4 \\
39.4 \\
30.0 \\
30.0\end{array}$ & $\begin{array}{l}26.8 \\
25.6 \\
26.8 \\
25.6\end{array}$ & $\begin{array}{l}46.3 \\
43.9 \\
45.7 \\
46.8\end{array}$ \\
\hline
\end{tabular}

sumed that this brief integration process is initiated at stimulus onset, and that it may not operate in series with a longer term integrator when interaural parameters differ. In combined forward-backward masking, a short-term integration process with these characteristics would be initiated at onset of the forward masker and continue to summate auditory input for a brief interval of 5-10 msec. One might therefore expect that additional masking would differ for transients that occurred within this interval and those that did not. This hypothesis was tested in Experiment 4 by varying the duration of the maskers in a combined forward-backward masking paradigm.

\section{Method}

The silent interval between click and masker onset or offset was fixed at $1 \mathrm{msec}$, and thresholds were determined for diotic and dichotic high- and low-pass transients in forward, backward, and combined forward-backward masking configurations. Duration of the maskers was either 3 or 300 msec. Subjects and procedures were the same as those employed in the previous experiment.

\section{Results}

For each of the subjects, thresholds in decibels SL are listed for the low-pass click in Table 2 and for the highpass click in Table 3. The amount of additional masking, or masking in excess of that predicted from the intensity sum of the maskers presented alone, is shown for both low- and high-pass transients in Figure 5. Values plotted are means for the two subjects. For instances in which differences between the observers exceeded $2 \mathrm{~dB}$, the range of scores is indicated by horizontal bars.

For the low-pass click, additional masking was quite minimal for both diotic and dichotic stimulus conditions and showed no consistent differences as a function of the duration of the forward masker. This was not the case for the high-pass transient. Decreasing the duration of the forward masker from 300 to $3 \mathrm{msec}$ increased the amount of additional masking for the monaural high-pass click by 9-12 dB, depending upon duration of the backward masker. A similar increase in additional masking was also observed for the diotic high-pass click, although the effect was smaller, ranging from $4 \mathrm{~dB}$ when duration of the backward masker was $300 \mathrm{msec}$ to $8 \mathrm{~dB}$ when it was $3 \mathrm{msec}$. Examination of the thresholds listed in Table 3 indicates that for high-pass transients, the amount of masking for both diotic and dichotic stimuli was nearly equivalent for all forward-backward masking configurations. Thus, despite the fact that thresholds for transients centered within a noise burst continue to increase with increases in masker duration up to approximately 20 $30 \mathrm{msec}$ (Penner et al., 1972), when the click was cen- 


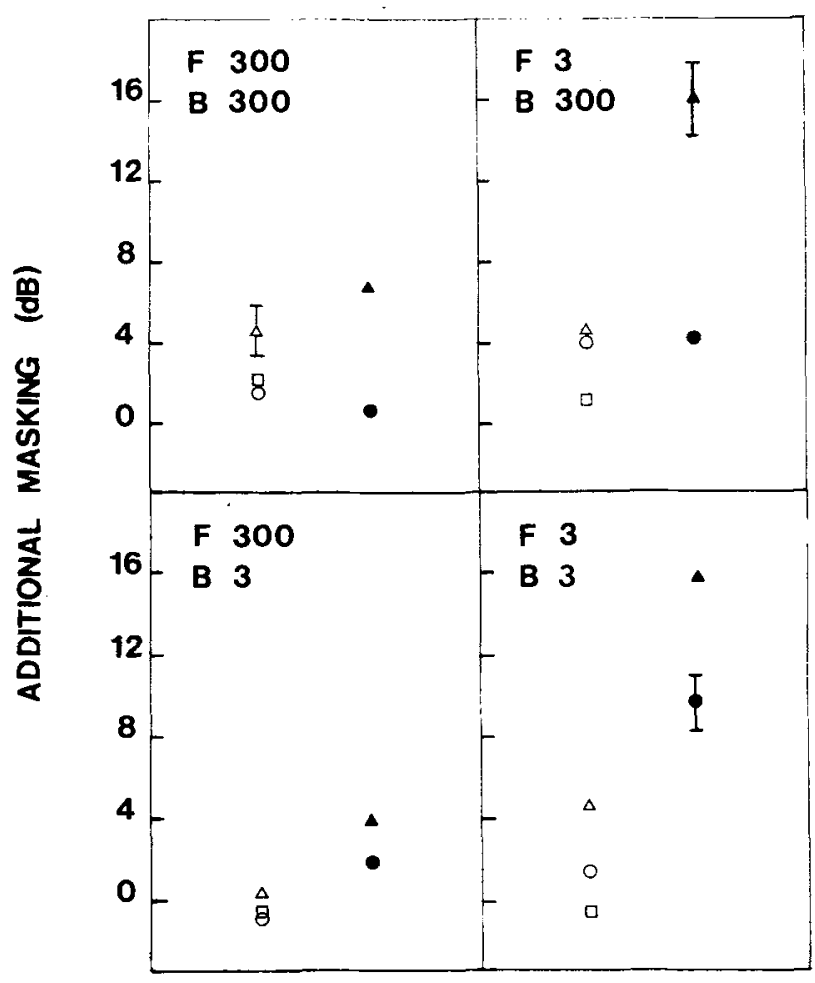

Figure 5. Additional masking for low- and high-frequency diotic and dichotic transients for forward- and backward-masker durations of 3 and 300 msec. Masker durations are indicated at the upper left of each panel. Intervals between the click and masker onset and offset were 1 msec. Open symbols denote low-frequency transients; closed symbols denote high-frequency transients. Circles, squares, and triangles represent NaSo, NaS $\pi$, and NaSm conditions, respectively. Data are means for two observers. Horizontal bars indicate the range of scores for instances in which differences between observers exceeded 2 dB.

tered within a gap between two noise bursts, a combined masker duration of $6 \mathrm{msec}$ produced as much masking as one of $600 \mathrm{msec}$.

\section{GENERAL DISCUSSION}

The existence of two parallel systems specialized for processing transient and sustained aspects of stimulation has been well established for the visual system (Breitmeyer \& Ganz, 1976), and a similar organization of the auditory system has been inferred from differences between detection and recognition performance in perceptual tasks (Macmillan, 1971, 1973), from analysis of reaction time data (Burbeck \& Luce, 1982) and from the response characteristics of auditory neurons (Gersuni, 1971). The results of the present series of experiments also appear to be consistent with this type of organization if, in addition, one assumes that information from short- and longterm integration systems is combined at higher centers when analysis of interaural differences within each of the systems yields similar estimates of lateral position or spa- tial location. Presumably, such estimates are based primarily on onset interaural differences in the short-term system and ongoing interaural differences in long-term integration. Within this framework, the high-frequency temporal MLD can be understood as the difference in detectability of a click when the results of short- and longterm processes are combined and when they are not. Thus, when a dichotic click is presented just prior to a diotic masker, interaural cues analyzed by short- and long-term integration systems indicate discrepant spatial locations and information from the two integrators is processed independently. However, when both click and masker are diotic, spatial locations coincide and the output of the short-term integrator is combined with the result of a longer integration process which includes considerably more of the masker. The contribution of this second integration process is evident in the results of Experiment 3, which showed that increases in backward-masker duration produced substantial increases in threshold for diotic clicks but had little effect on detectability of monaural stimuli. The demonstration in Experiment 1 of an orderly increase in the size of the MLD with increasing interaural time differences implies that the degree of similarity between interaural parameters analyzed by short- and long-term integration systems determines the extent to which information from the two integrators is combined.

Several characteristics of the short-term integrator may be inferred from these data. First, the fact that large MLDs were found for high-frequency monaural transients as well as for transients presented with an interaural temporal delay suggests that, for high frequencies, the short-term integration system is sensitive both to interaural differences in intensity and to interaural temporal differences in the stimulus envelope. For low frequencies, it appears to be sensitive to interaural differences in intensity and phase. The finding that thresholds for low-pass $\mathrm{S} \pi$ clicks in Experiment 2 were approximately $10 \mathrm{~dB}$ lower immediately after masker onset than in continuous masking presumably reflects this sensitivity to cycle-by-cycle phase differences in the short-term integration system.

Second, the absence of high-frequency MLDs in simultaneous masking and their reduced amplitude in forward masking suggests that the short-term integrator may reflect many properties of an onset detector, exhibiting refractoriness during continued stimulation and for a brief period after stimulus offset. Moller (1969) has reported that the response of "on units" in the cochlear nucleus of the rat is completely inhibited in the presence of noise. When stimulated by click trains, these units respond to each click at low repetition rates, but gradually shift to a single discharge at train onset as the repetition rate is increased. Under these conditions, the probability of response appears to be determined by the duration of the silent period between stimuli rather than by repetition rate per se. The recent work of Hafter and his associates (Dye \& Hafter, 1984; Hafter \& Dye, 1983; Hafter, Dye, \& Wenzel, 1983) demonstrates another parallel between the response properties of these "on" type units and interaural dis- 
crimination in human subjects. In a series of studies examining detection of both interaural time and intensity differences in trains of high-frequency clicks, these investigators found that the amount of information contributed by each click was gradually reduced as the interclick interval decreased from 10 to $1 \mathrm{msec}$. In addition, studies of the precedence effect have described a similar lapse of interaural sensitivity lasting for approximately $10 \mathrm{msec}$ after the abrupt onset of an auditory stimulus (Zurek, 1980).

The response characteristics of an onset detector may also account for at least a portion of the additional masking observed in Experiment 4. The argument is similar in many respects to the "two cues" explanation of additional masking outlined by Green (1967). Given that the threshold of a high-pass click in the presence of a backward masker is determined to some extent by the response of an onset detector, one would expect that the addition of a forward masker would render this detector refractory and thus obliterate the onset cue. Since the onset response provides the primary cue for detection of dichotic stimuli when maskers are diotic, one would also expect that elimination of this cue would have a greater effect on thresholds (i.e., result in more additional masking) for dichotic than for diotic transients, as the results of Experiment 4 demonstrate. The large difference in amounts of additional masking seen for high- and low-pass stimuli suggests that the onset response plays a more critical role in detection of high-frequency transients. This may be related to Henning's $(1980,1983)$ finding that subjects are unable to lateralize low-frequency stimuli solely on the basis of an interaural delay in the envelope. Since both systems appear to be sensitive to interaural differences in phase at low frequencies, the short-term integrator would not provide any information unique to onset.

The observation that forward and backward maskers only $3 \mathrm{msec}$ in duration produced asymptotic levels of masking when presented in combination is more difficult to explain, but clearly indicates that nonlinear interactions may occur between stimuli when intervals between onsets are brief. One possible explanation is that the close proximity of forward masker onset served to reduce the onset response to the click, thus indirectly increasing the effectiveness of the backward masker. This would require the assumption that the click normally inhibits the response to backward masker onset in the absence of a forward masker. However, there was little evidence of suppressive interactions between these stimuli in the fringe masking conditions of Experiment 2. Alternatively, it may be that three onsets occurring within the summating period of the short-term integrator produce asymptotic response levels, and that signal-to-masker ratios necessary for detection under asymptotic conditions are similar in both long- and short-term integrating systems. In any case, the fact that results were similar for diotic and dichotic stimuli provides further support for the view that short-term integration is not limited to the binaural system, but is a general characteristic of auditory processing.

\section{REFERENCES}

BERG, K., \& Yost, W. (1976). Temporal masking of a click by noise in diotic and dichotic listenting conditions. Journal of the Acoustical Society of America, 60, 173-177.

BernsteIN, L. R., \& TrahIOTIS, C. (1982). Detection of interaural delay in high-frequency noise. Joumal of the Acoustical Society of America, $71,147-152$.

BREITMEYER, B. G., \& GANZ, L. (1976). Implications of sustained and transient channels for theories of visual pattern masking, saccadic suppression, and information processing. Psychological Review, 83, 1-36.

BURbECK, S. L., LuCE, R. D. (1982). Evidence from auditory simple reaction times for both change and level detectors. Perception \& Psychophysics, 32, 117-133.

ColbuRN, H. S. (1977). Theory of binaural interaction based on auditory-nerve data. II. Detection of tones in noise. Journal of the Acoustical Society of America, 61, 525-533.

Colburn, H. S., \& Durlach, N. I. (1978). Models of binaural interaction. In E. Carterette \& M. Friedman (Eds.), Handbook of perception: Vol. 4, Hearing. New York: Academic Press.

Deatherage, B. H., \& Evans, T. R. (1969). Binaural masking: Backward, forward, and simultaneous effects. Joumal of the Acoustical Society of America, 46, 362-372.

Dolan, T. R., Trahiotis, C. (1972). Binaural interaction in backward masking. Perception \& Psychophysics, 11, 92-94.

DuIFHuIs, H. (1973). Consequences of peripheral frequency selectivity for nonsimultaneous masking. Journal of the Acoustical Society of America, 54, 1471-1488.

DURLACH, N. I. (1972). Binaural signal detection: Equalization and cancellation theory. In J. V. Tobias (Ed.), Foundations of modern auditory theory (Vol. 2). New York: Academic Press.

Durlach, N. I., Colburn, H. S. (1978). Binaural phenomena. In E. Carterette \& M. Friedman (Eds.), Handbook of perception: Vol. 4, Hearing. New York: Academic Press.

DYe, R. H., HAFTER, E. R. (1984). The effects of intensity on the detection of interaural differences of time in high-frequency trains of clicks. Joumal of the Acoustical Society of America, 75, 1593-1598.

Flanagan, J. L., \& Watson, B. J. (1966). Binaural unmasking of complex signals. Joumal of the Acoustical Society of America, 40, 456-468.

GersuNI, G. V. (1971). Temporal organization of the auditory function. In G. V. Gersuni (Ed.), Sensory processes at the neuronal and behavioral levels. New York: Academic Press.

GREEN, D. M. (1967). Additivity of masking. Journal of the Acoustical Society of America, 41, 1517-1525.

GreEN, D. M., \& Yost, W. A. (1976). Binaural analysis. In W. Keidel \& D. Neff (Eds.), Handbook of sensory physiology (Vol. 5). Berlin, Heidelberg, and New York: Springer-Verlag.

HAFTER, E. R., \& DEMAIo, J. (1975). Difference thresholds for interaural delay. Joumal of the Acoustical Society of America, 57, 181-187.

HAFTER, E. R., DYE, R. H. (1983). Detection of interaural differences of time in trains of high-frequency clicks as a function of interclick interval and number. Joumal of the Acoustical Society of America, 73, 644-651.

Hafter, E. R., Dye, R. H., \& Wenzel, E. (1983). Detection of interaural differences of intensity in trains of high-frequency clicks as a function of interclick interval and number. Journal of the Acoustical Society of America, 73, 1708-1713.

Henning, G. B. (1974a). Detectability of interaural delay in highfrequency complex waveforms. Journal of the Acoustical Society of America, 55, 84-90.

HenNing, G. B. (1974b). Lateralization and the binaural masking-level difference. Joumal of the Acoustical Society of America, 55, 1259-1262.

Henning, G. B. (1980). Some observations on the lateralization of complex waveforms. Joumal of the Acoustical Society of America, 68 , 448-454.

HenNING, G. B. (1983). Lateralization of low-frequency transients. Hearing Research, 9, 153-172.

Henning, G. B., \& Gaskell, H. (1981). Binaural masking level differences with a variety of waveforms. Hearing Research, 4, 175-184. 
JEFFRESS, L. A. (1972). Binaural signal detection: Vector theory. In J. V. Tobias (Ed.), Foundations of modern auditory theory (Vol. 2). New York: Academic Press.

LAKEY, J. R. (1976). Temporal masking-level differences: The effect of mask duration. Journal of the Acoustical Society of America, 59, 1434-1442.

LEVITT, H. (1971). Transformed up-down methods in psychoacoustics. Journal of the Acoustical Society of America, 49, 467-477.

MaCmillan, N. A. (1971). Detection and recognition of increments and decrements in auditory intensity. Perception \& Psychophysics, 10, 233-238.

MacmillaN, N. A. (1973). Detection and recognition of intensity changes in tone and noise: The detection-recognition disparity. Perception \& Psychophysics, 13, 65-75.

MCFADDEN, D. (1966). Masking-level differences with continuous and with burst masking noise. Joumal of the Acoustical Society of America, 40, 1414-1419.

McFadden, D., \& Pasanen, E. G. (1976). Lateralization at high frequencies based on interaural time differences. Joumal of the Acoustical Society of America, 59, 634-639.

Moller, A. R. (1969). Unit responses in the rat cochlear nucleus to repetitive, transient sounds. Acta Physiologica Scandinavica, 75, 542-551.

Munson, W. A. (1947). The growth of auditory sensation. Journal of the Acoustical Society of America, 19, 584-591.

NUETZEL, J. M., \& HAFTER, E. R. (1976). Lateralization of complex waveforms: Effects of fine structure, amplitude, and duration. Journal of the Acoustical Society of America, 60, 1339-1346.

PenNer, M. J. (1974). Effect of masker duration and masker level on forward and backward masking. Journal of the Acoustical Society of America, 56, 179-182.

PenNer, M. J. (1980). Evidence for two temporal processes in forward masking. Joumal of the Acoustical Society of America, 68, 455-457.

Penner, M. J., \& Cudahy, E. (1973). Critical masking interval: A temporal analog of the critical band. Journal of the Acoustical Society of America, 54, 1530-1534.

Penner, M. J., Cudahy, E., \& Jenkins, G. W. (1974). The effect of masker duration on forward and backward masking. Perception \& Psychophysics, 15, 405-410.

Penner, M. J., Robinson, C. E., Green, D. M. (1972). The critical masking interval. Joumal of the Acoustical Society of America, $52,1661-1668$.
Robinson, D. E., \& Trahiotis, C. (1972). Effects of signal duration and masker duration on detectability under diotic and dichotic listening conditions. Perception \& Psychophysics, 12, 333-334.

Small, A. M., Bogess, J., Klich, R., Kuehn, D., Thelin, J., \& WILEY, T. (1972). MLDs in forward and backward masking. Journal of the Acoustical Society of America, 51, 1365-1367.

Trahiotis, C., Dolan, T., Miller, T. (1972). Effect of "backward" masker fringe on the detectabiity of pulsed diotic and dichotic tonal signals. Perception \& Psychophysics, 12, 335-338.

Wilson, R. H., \& CARHART, R. (1971). Forward and backward masking: Interactions and additivity. Journal of the Acoustical Society of America, 49, 1254-1263.

YosT, W. A. (1976). Lateralization of repeated filtered transients. Journal of the Acoustical Society of America, 60, 178-181.

Yost, W. A., Dolan, D. (1978). Masking-level differences for repeated filtered transients. Journal of the Acoustical Society of America, 63, 1927-1930.

Yost, W. A., \& Silva, D. (1977). Binaural processing of filtered transients. Sensory Processes, 1, 363-375.

Yost, W. A., WightmaN, F. L., \& GREEN, D. M. (1971). Lateralization of filtered clicks. Journal of the Acoustical Society of America, 50, 1526-1531.

Young, L. L., \& CARHART, R. (1974). Time-intensity trading functions for pure tones and a high-frequency AM signal. Journal of the Acoustical Society of America, 56, 605-609.

ZERLIN, S. (1966). Interaural time and intensity difference and the MLD. Journal of the Acoustical Society of America, 39, 134-137.

ZUREK, P. M. (1979). Measurements of binaural echo suppression. Journal of the Acoustical Society of America, 66, 1750-1757.

ZUREK, P. M. (1980). The precedence effect and its possible role in the avoidance of interaural ambiguities. Joumal of the Acoustical Society of America, 67, 952-964.

ZWICKER, U. T., \& ZWICKER, E. (1984). Binaural masking-level difference as a function of masker and test-signal duration. Hearing Research, 13, 215-219.

ZwISLOCKI, J. (1960). Theory of temporal auditory summation. Journal of the Acoustical Society of America, 32, 1046-1060.

ZWISLOCKI, J. (1969). Temporal summation of loudness: An analysis. Journal of the Acoustical Society of America, 46, 431-441.

(Manuscript received October 25, 1984; revision accepted for publication March 18, 1985.) 